\title{
Text Mining and Citation Network of Ecosystem Services Publications
}

\section{Muhammad Malik Ar Rahiem}

Institute of Applied Geosciences, Technische Universität Darmstadt

*Correspondence: muhammadmalik.arrahiem@stud.tu-darmstadt.de

\begin{abstract}
:
Ecosystem Services is an important concept to achieve Sustainable Development Goals 2030. For the past 20 years, this concept has grown exponentially and the metadata of these publications can be considered as big data. A bibliometric analysis was conducted to Ecosystem Services publications from Web of Science database, which are text-mining analysis, bibliographic coupling, and citation network analysis. Text-mining analysis results were a cluster map of keywords representing the content of abstract and title from 4203 publications in the dataset. Bibliographic coupling analysis results were a cluster of documents which analyzed using natural language processing to extract the main idea of the documents. Using these two analysis insight about ecosystem services are obtained. Ecosystem services in general can be divided into 6 big clusters: economic assessment of ecosystem services as natural capital, ecosystem services assessment in term of accounting and management, biodiversity conservation in term of species richness, biodiversity conservation in term of human well-being, climate change and ecosystem services, and ecosystem services in urban area. Finally, citation network analysis was performed. 5700 publications consist of publications from the dataset and cited references from the publications were analyzed and 50 most influential articles from 1977 to 2018 with highest citation score was plotted in chronological order, providing insight on how the topic has been developing over time and important publications to be read. Bibliometric analysis proved to be very useful, especially as the preliminary step before conducting literature review. This technique can be very beneficial for early career scientists who wanted to recognize a field of science or wanted to know the research gaps that could be worked on.
\end{abstract}

Keywords: bibliometric analysis, ecosystem services, bibliographic coupling, text-mining, citation network

\section{Introduction}

The concept of ecosystem services (ES) has been acknowledged as an important concept to achieve Sustainable Development Goal (SDG). A study shows that Ecosystem Services make an important contribution to 41 from 169 SDG targets (Wood et al., 2018). It is believed that by integrating ecosystem services, the benefits nature provides to people, into strategies for meeting the SDGs can help achieve well-being for all while protecting the environment, a central idea in the SDGs. Ecosystem services itself can be described as the benefits people obtain from ecosystems (Millennium Ecosystem Assessment, 2005).

The concept has been developing for almost 50 years, at least since the 70s (Gómez-Baggethun et al., 2010). But the concept starts booming out in 1997 when Costanza published their research "The value of the world's ecosystem services and natural capital" which remarked this subject to become very important (Chaudhary et al., 2015). This research became the most important publications in this topic, shown in their number of citations. After 1997, the publications in this topic has grown exponentially as shown in the Figure-1 below. 


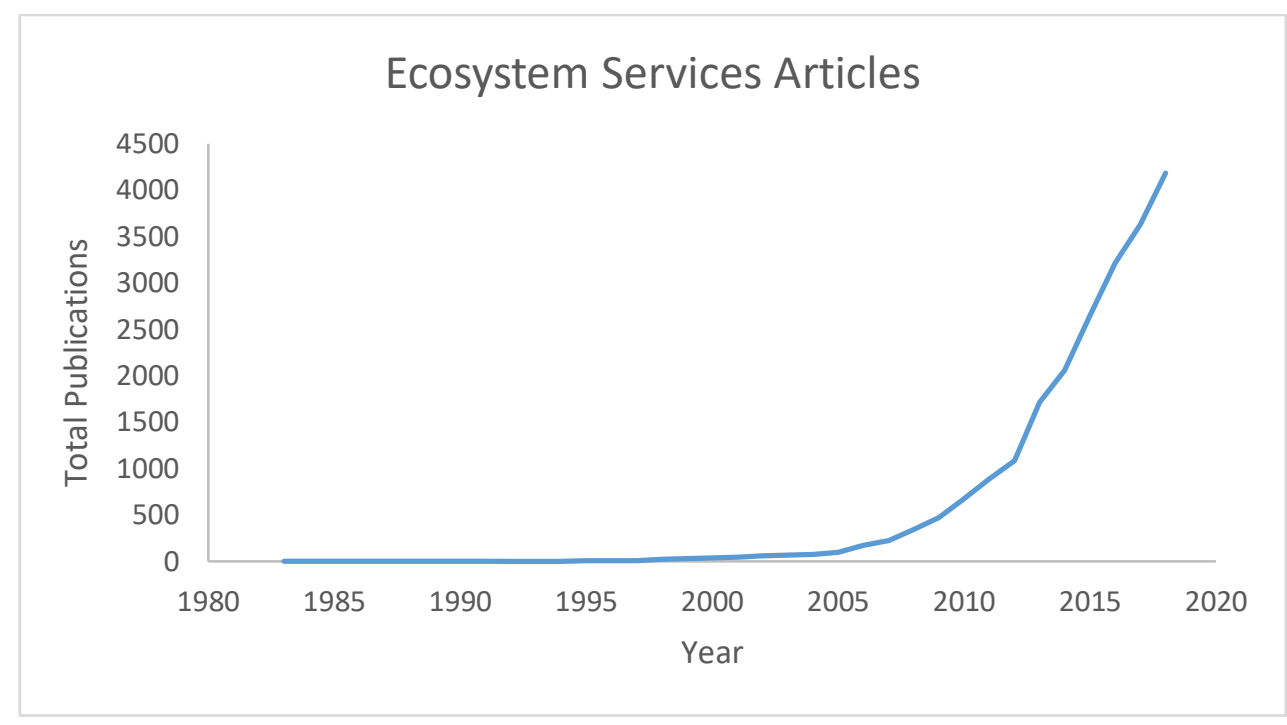

Figure-1 Source: Web of Science 3/10/2019

Search results in Scopus (www.scopus.com) per 14 October 2018 with the keyword "Ecosystem Services" within title, abstract, and keywords, resulting 23.166 documents, while using Web of Science (https://apps.webofknowledge.com/) within topic "Ecosystem Services" resulting 20.535 publications.

Not so many realize that current database of this topic is already huge dataset that can be used to create a pattern on how this topic has been developing over time. Each article contains metadata such as text on its title, keywords, abstract, institutions, citations, countries, and so on. With the list containing more than 20.000 articles, this relationship between each dataset can result in a pattern which can be interpreted to understand better on what has been going in this topic. Text can be analyzed using text-mining analysis, authors can be grouped according to their citation preferences, and many other possibility.

The study on interrelated bodies of documents is called bibliometrics study. One of the best-known applications for this study is the comparative evaluation of countries, universities, research institutes, and individual researchers, but it can also be used for other purposes such as to obtain better understanding of the structure of a field, or to determine the development in research topic (Waaijer and Palmblad, 2015).

Bibliometric analysis is nowadays also very easy to be performed because there are programs already develop to simply perform bibliometric mapping. Many techniques have been developed and have its own function as explained in the list in Table-1 below. Recent techniques enable us to perform bibliometric analysis using a computer without the needs to calculate sophisticated statistical background behind the process.

Table-1 URLs of the website of a number of software tools that can be used for visualizing bibliometric networks (van Eck and Waltman, 2014a).

\begin{tabular}{|c|c|c|}
\hline Software & Function Design & Web Address \\
\hline Pajek & \multirow{2}{*}{ General network analysis tools } & http://pajek.imfm.si \\
\hline Gephi & & https://gephi.org/ \\
\hline CiteSpace & \multirow{3}{*}{$\begin{array}{l}\text { Developed specifically for } \\
\text { analyzing and visualizing } \\
\text { bibliometric networks }\end{array}$} & http://cluster.cis.drexel.edu/ cchen/citespace/ \\
\hline $\mathrm{Sci}^{2}$ & & https://sci2.cns.iu.edu \\
\hline VOSViewer & & http://www.vosviewer.com \\
\hline CitNetExplorer & \multirow{2}{*}{$\begin{array}{l}\text { Analysis and visualization of } \\
\text { citation networks of publications }\end{array}$} & http://www.citnetexplorer.nl/ \\
\hline HistCite & & http://www.histcite.com \\
\hline
\end{tabular}


In this articles, bibliometric studies were performed using two techniques developed by Nees Jan van Eck and Ludo Waltman from University of Leiden called VOS, which stands for visualizations of similarities (van Eck et al., 2010) and CitNetExplorer which stands for Citation Network Explorer. VOSviewer has been used for constructing bibliometric maps in a countless of studies (see the list here). While citation network from CitNetExplorer can be used to study the development of any research field, to delineate the literature on a research topic, and to support literature reviewing (van Eck and Waltman, 2014b).

This article aims to perform a bibliometric analysis of Ecosystem Services research using three approaches. The first approach was text mining analysis within words contained in the abstract and titles of ecosystem services research. This resulted in co-words map, which is especially well-suited to obtain an overview of a field, as they show the main terms used in that field (Waaijer and Palmblad, 2015). This analysis generated a cluster of keywords which can show the broad spectrum in this topic. The second approach was to categorize articles within Ecosystem Services research using bibliographic coupling. The third approach was to place every article within Ecosystem Services research in the right order according to the year it was published and the citation network between each publication. Citation network of publications shows the most important publications in a field, ordered by the year in which they published, and the citation relations between these publications over time (van Eck and Waltman, 2014b).

\section{Materials and Methods}

The data used for this study were taken in October 2018 from the Web of Science bibliographic database produced by Thomson Reuters. Web of Science is a platform containing regional citation index, patent data, specialized subject indexes, and an index of research data sets, all in totaling over 33.000 journals, one of the most accurate, objective, and complete resource available for bibliographic study.

In this study, total of 4203 articles metadata containing "Ecosystem Services" within its title are extracted. Unfortunately, for complete metadata, Web of Science limits the number of download to only 500 download. The timespan of the publications is set to be from 1945-2019. The database supports various file formats. The tab-delimited format was used in this study. The dataset that was used can be accessed here. In total there are 964.820 tokens, 848.528 words, and 32.381 sentences present in this dataset.

Text mining analysis was conducted using VOSviewer. This analysis was conducted to the text data contained in the title and abstract of the publications. The authors have put a lot of effort to summarize the articles into 300 words of abstract and a sentence of title, therefore these can be considered as the main idea and summary of any publications. However recent study founds that text mining full research articles gave consistently better results than text mining abstract (Westergaard et al., 2018).

Binary counting method was chosen instead of full counting. This means that only the presence or the absence of a term in a document matters. The number of occurrences of a term in a document is not taken into account. The threshold of the term was set into 20. It means that the words need to be occur minimum 20 times in the database to be considered. The result of this analysis is a map containing clustered dots representing words extracted from titles and abstracts.

The mathematical background behind clustering analysis in VOSViewer explained further in the article by Van Eck and Waltman, 2010. Using this method, elements of the articles were assigned into twodimensional space. The distance between the two points reflects the similarity between those elements as accurately as possible. The closer the distance is, the stronger their relationship between this element. 
Bibliographic coupling analysis was conducted using VOSviewer. Bibliographic coupling is a term introduced by Dr. Kessler from Massachusetts Institute of Technology in 1963, that says, "Scientific articles bear a meaningful relation to each other (they are coupled) when they have one or more references in common" (Kessler, 1963; Weinberg, 1974). The reverse of bibliographic coupling is cocitation relationship. Two articles have co-citation relationship when they are cited by the third articles. It can be debatable whether bibliographic coupling really shows the relationship between publications. However, bibliographic coupling is proven to be an appropriate method for science mapping purposes (Jarneving, 2007). Co-citation is accurate markers for the emergence of new topics, while bibliographic coupling is more retrospective (Garfield, 2001)

When executing bibliographic coupling of documents, 20 citations were used as the threshold. It means only documents with minimum of 20 citations can be considered. The result of bibliographic coupling is also set of clusters. Afterward, article titles from each cluster were extracted and analyzed using Keyword tools on Sketch Engine (https://www.sketchengine.eu/), an online linguistics tools that can be used for text analysis or text mining applications. The result was words and terms which considered as representative of the documents clusters and then visualize as word clouds using https://www.wordclouds.com/, an online word clouds generator which available for free.

Citation Network Analysis was conducted using CitNetExplorer, a powerful tool to analyze citation network. This analysis shows the most important publications in a field, ordered by the year they appeared, and the citation relations between these publications, which represent the picture of the development of a field over time (van Eck and Waltman, 2014b).

The flowchart on how the data are processed is shown in the Figure- 2 below:

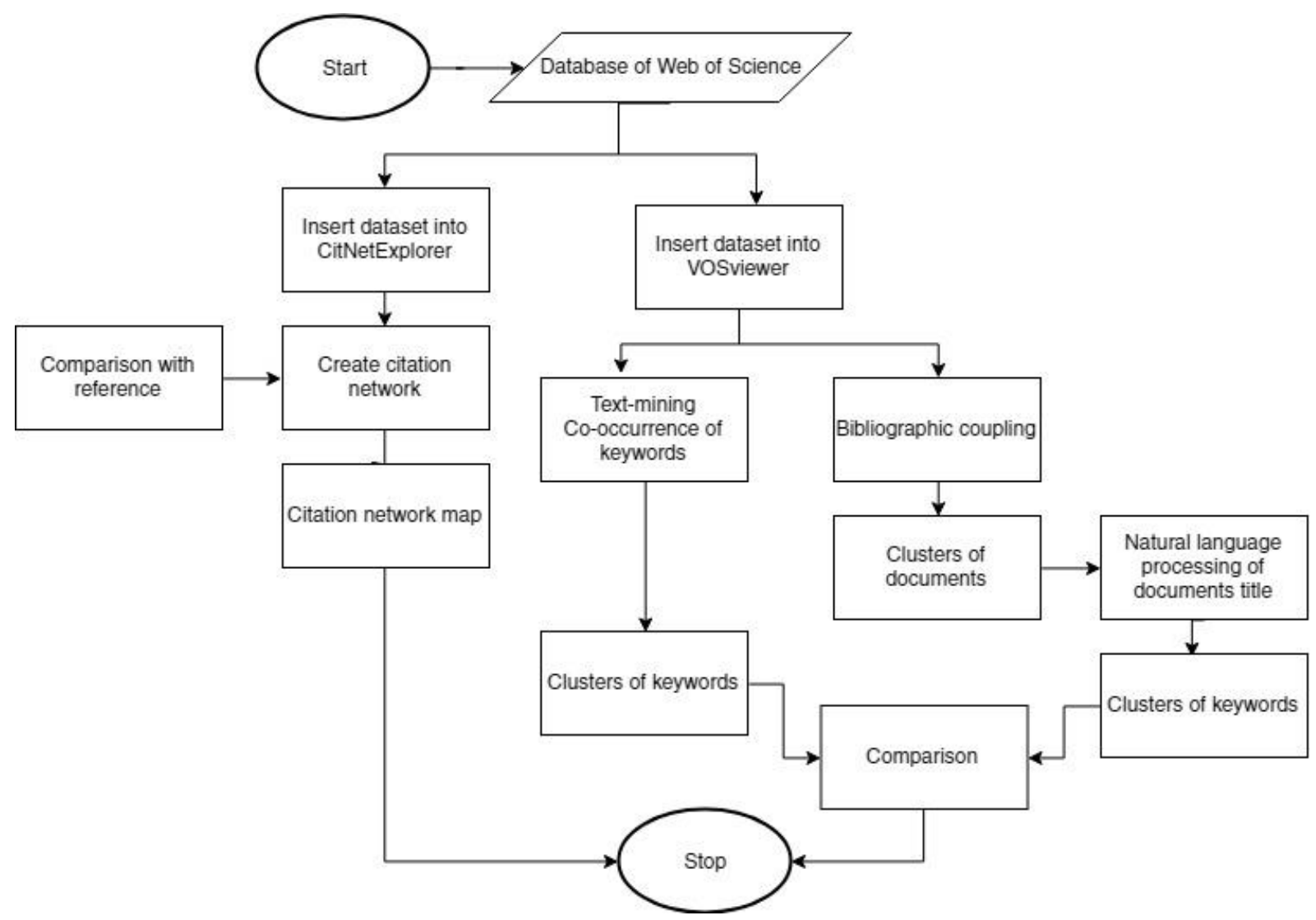

Figure-2 the stages of analysis in ecosystem services bibliographic study. 


\section{Results}

\subsection{Text Mining With VOSviewer}

Co-occurrence map based on text data from title and abstract was created using VOSviewer. Using 20 occurrences as a threshold, 613 terms were selected and clustered into 6 clusters, which are visualized in Figure-3 below:

An interactive version of the visualization of Figure-3 is available online at http://bit.ly/TitleAndAbstract and the tables containing information of the clustering can be accessed here.

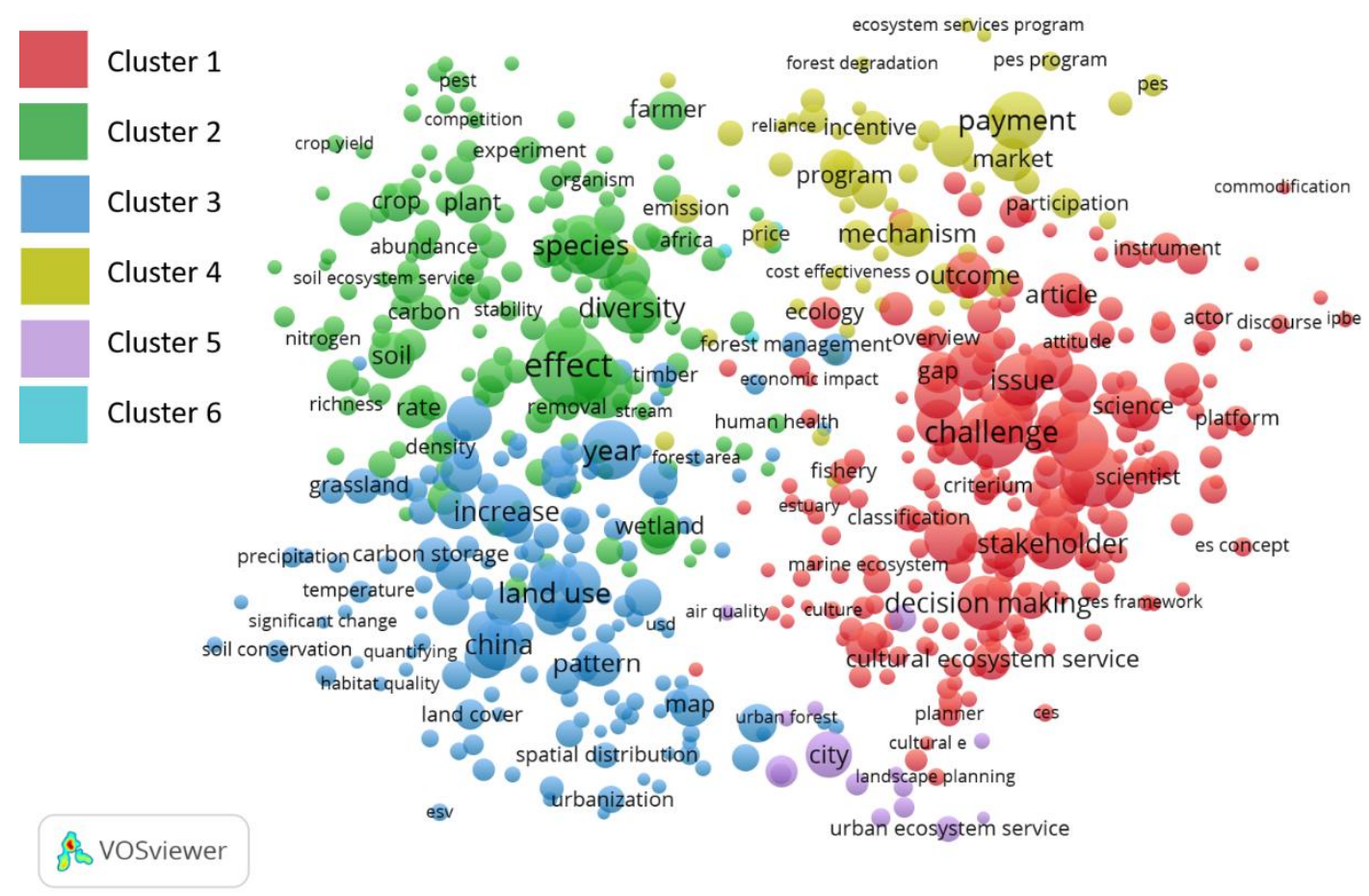

Figure-3 Clusters map produced by co-occurrences of text using VOSViewer showing distinguishable 6 clusters in Ecosystem Services articles in Web of Science Database.

Figure oben is showing co-occurrence relationship between each word contained in the title and abstract dataset of Ecosystem Services publications. The color is showing the cluster, and the dot is showing the words. The bigger the dot, the more frequent the word occurs in the articles. The distance between two dots approximately indicates the relatedness of the dots in terms of co-occurrences.

While some dots are overlapping each other, most of the dots formed distinguishable clusters. Cluster 1 contains 232 items. Cluster 2 contains 157 items. Cluster 3 contains 148 items. Cluster 4 contains 58 items. Cluster 5 contains 15 items, and cluster 6 only contains 3 items, therefore can be neglected.

To summarize each clusters, the 10 most frequent words that occur in each cluster are considered as representatives shown in Table-2.

Even though the clusters seem to be easily distinguished, the interpretation of the cluster was not as easy. Some cluster can be easily interpreted, for example, cluster 4 with keywords related to the economy, payment mechanism, and scheme. Cluster 5 can also be easily interpreted as ecosystem services in an urban area because of the relatedness of the keyword to a specific topic of an, urban area. Cluster 1, 2, and 3, however, were not so obvious to interpret. 


\begin{tabular}{|c|c|c|}
\hline $\begin{array}{l}\overline{\bar{g}} \\
\overline{\underline{z}} \\
\bar{u}\end{array}$ & $\begin{array}{l}\text { No of } \\
\text { Words }\end{array}$ & Most frequent words in the cluster \\
\hline 1 & 232 & $\begin{array}{l}\text { Challenge (537), concept (486), nature (404), decision making (340), issue (327), } \\
\text { stakeholders (321), valuation (321), perspective (311), implementation (291), } \\
\text { literature (277) }\end{array}$ \\
\hline 2 & 157 & $\begin{array}{l}\text { Effect (732), species (424), loss (408), diversity (324), agriculture (302), climate change } \\
(290) \text {, soil (258), food (221), reduction (200), wetland (200), crop (175), plant (177) }\end{array}$ \\
\hline 3 & 148 & $\begin{array}{l}\text { Year (420), land use (389), increase (326), china (317), carbon sequestration (236), } \\
\text { pattern (231), land use change (212), multiple ecosystem services (202), synergy (206) }\end{array}$ \\
\hline 4 & 58 & $\begin{array}{l}\text { Payment (401), mechanism (234), program (229), market (222), scheme (199), } \\
\text { livelihood (155), incentive (138), income (135), participation (114), willingness (113), } \\
\text { effectiveness (112) }\end{array}$ \\
\hline 5 & 15 & $\begin{array}{l}\text { City (258), urban area (129), resident (92), urban ecosystem service (79), green } \\
\text { infrastructure (65), urban development (52), urban planning (51), green space (48) }\end{array}$ \\
\hline
\end{tabular}

Cluster 1 with keywords such as challenge, concept, implementation, valuation, etc, mostly related to the major concept of ecosystem services. Cluster 2 with words such as effect, species, diversity, agriculture, reduction, rate, plant, wetlands can be interpreted as provision services of an ecosystem. Cluster 3 with major keywords of land use, land use change, year, carbon sequestration, and especially pattern can be interpreted as spatial changes in ecosystem services.

\subsection{Bibliographic Coupling}

The second approach was the bibliographic coupling analysis. Using the same dataset, with thresholds of 20 citations, 4203 documents are analyzed, and 1138 documents meet the threshold. All of the dots were clustered into 6 clusters. Cluster 1 has 250 items, cluster 2 has 236 items, cluster 3 has 186 items, cluster 4 has 135 items, cluster 5 has 116 items, and cluster 6 has 77 items. Visualization of the bibliographic coupling are shown in Figure-4.

Interactive visualization of this map can be accessed in this page http://bit.ly/bibliographiccoupling. 


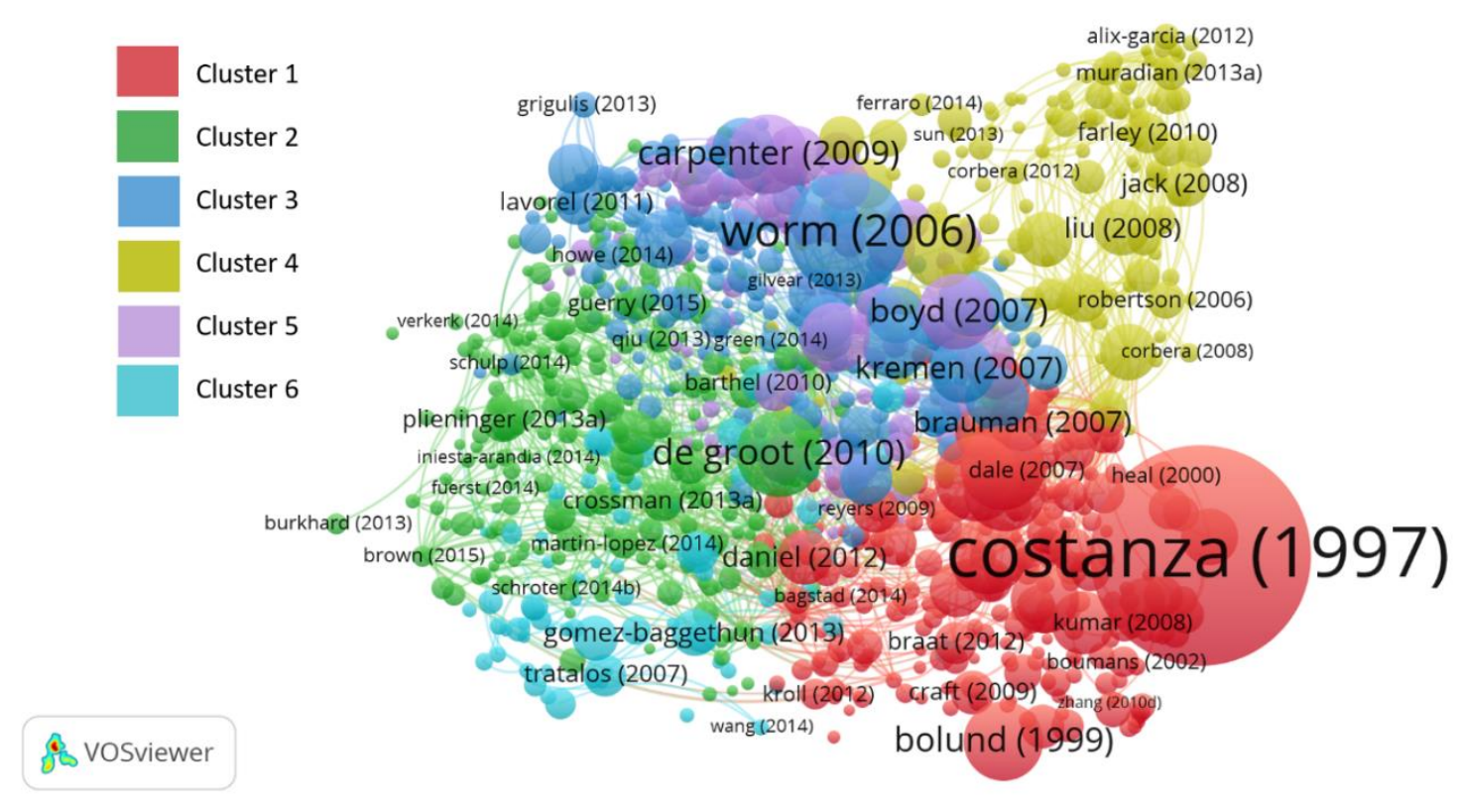

Figure-4 Cluster maps from bibliographic coupling analysis to Ecosystem Services research.

From figure oben we can obviously see clustered documents labeled with the first author of the publications and the year the article was published. We can recognize some major articles, symbolized by bigger dot, that contained in each cluster such as Cluster 1: Costanza (1997), Cluster 2: de Groot (2010), Cluster 3: Worm (2006), Cluster 4: Daily (2009), Gómez-Baggethun (2010), Cluster 5: Carpenter (2009), Bennet (2009), and Cluster 6: Pataki (2011), Gómez Baggethun (2013). These names are a popular name in ecosystem services research.

The title of every article in each cluster was then extracted to obtain the main idea of each cluster using natural language processing. Keywords and terms help us understand what the topic of the corpus is or how it differs from the reference corpus. By default, general language corpora are used as reference corpora to represent non-specialized language. Multi-words expressions were selected instead of single-words because it gives a more meaningful result.

The result of natural language processing is a set of multiword. Cluster 1 has 250 items, cluster 2 has 236 items, cluster 3 has 186 items, cluster 4 has 135 items, cluster 5 has 116 items, and cluster 6 has 77 items. Summary of the result is shown in the Table-3 below:

Table-3 Summary of natural language processing of the title and abstract in clusters of bibliographic coupling. Only 10 terms were selected from each cluster.

\begin{tabular}{|l|l|l|l|}
\hline $\begin{array}{l}\text { Clu } \\
\text { ster }\end{array}$ & $\begin{array}{l}\text { Total } \\
\text { Public } \\
\text { ations }\end{array}$ & $\begin{array}{l}\text { Total } \\
\text { Words }\end{array}$ & Multiwords \\
\hline 1 & 250 & 3110 & $\begin{array}{l}\text { Valuing ecosystem, natural capital, economic valuation, human well- } \\
\text { being, coastal ecosystem, forest ecosystem, management ecosystem, } \\
\text { cultural ecosystem, global ecosystem, marine ecosystem }\end{array}$ \\
\hline 2 & 236 & 2947 & $\begin{array}{l}\text { Cultural ecosystem, mapping ecosystem, multiple ecosystems, landscape } \\
\text { planning, mainstreaming ecosystem, land use, natural capital, mapping } \\
\text { cultural ecosystem, green infrastructure, land use planning }\end{array}$ \\
\hline 3 & 186 & 2278 & $\begin{array}{l}\text { Multiple ecosystems, managing ecosystem, grassland ecosystem, other } \\
\text { ecosystems, biodiversity conservation, human well-being, agricultural } \\
\text { landscape, crop pollination, plant diversity, species richness }\end{array}$ \\
\hline
\end{tabular}




\begin{tabular}{|l|l|l|l|}
\hline 4 & 135 & 1800 & $\begin{array}{l}\text { Poverty alleviation, latin America, biodiversity conservation, governing } \\
\text { ecosystem, water ecosystem, global biodiversity, water resource } \\
\text { management, current debate, human well-being, water resource }\end{array}$ \\
\hline 5 & 116 & 1418 & $\begin{array}{l}\text { Linking ecosystem, multiple ecosystems, natural capital, integrating } \\
\text { ecosystem, mainstreaming ecosystem, alluvial valley, millennium } \\
\text { ecosystem assessment, managing ecosystem, millennium ecosystem, } \\
\text { valuing ecosystem }\end{array}$ \\
\hline 6 & 77 & 1066 & $\begin{array}{l}\text { Urban ecosystem, green infrastructure, cultural ecosystem, urban green } \\
\text { space, urban forest, green space, regulating ecosystem, urban vacant land, } \\
\text { hedonic pricing, multiple ecosystems }\end{array}$ \\
\hline
\end{tabular}

Notice that the analysis in Table-3 resulted in multiword. To complete our understanding of the topic, single word analysis was also performed and visualized as word clouds in the Figure-5.
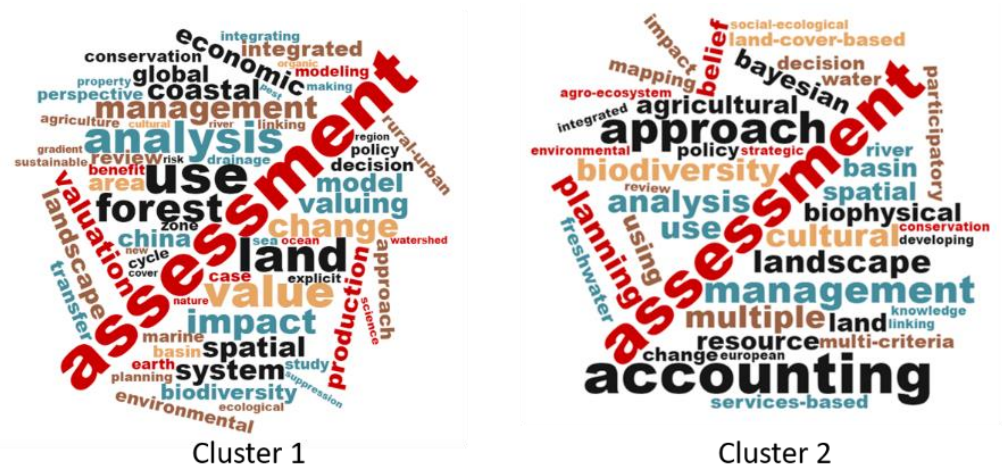

Cluster 2
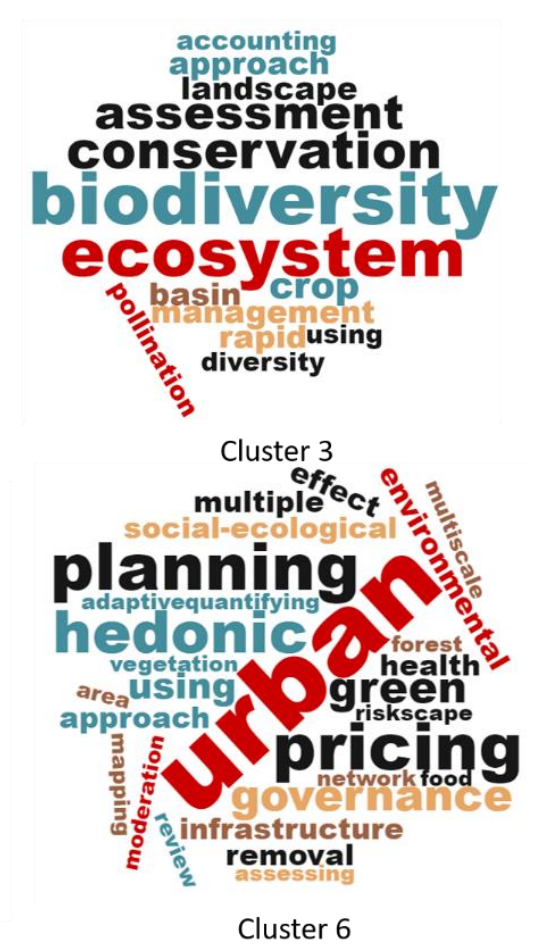

Cluster 4

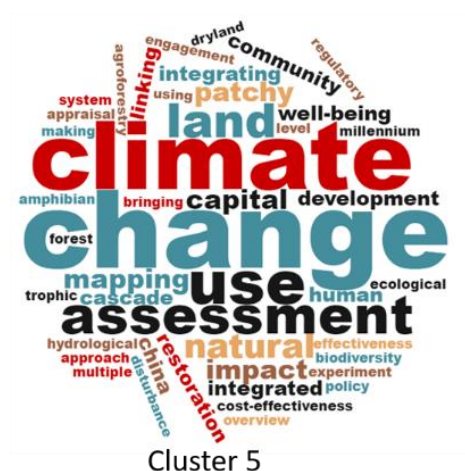

Figure-5 Wordclouds in the cluster from bibliographic coupling analysis

By combining the table result of multiword clustering and the single-word word clouds it is possible to interpret the title of each cluster.

Cluster-1 in Figure-5 shows "Assessment", "Analysis", "Forest", and "Land use" as its main keywords. Consider the result in Table-3, it can be interpreted that assessment in this cluster refers to economic assessment, especially as natural capital.

Cluster-2 in Figure-5 shows also "Assessment", but other keywords appear such as, "Accounting", "Management", and "Approach". The result in Table-3 shows some similar keywords, with only a few differences, such as "Multiple ecosystems" and "Landscape planning", these keywords are closer to management and approach. It can be interpreted that this cluster refer to management and approach in ecosystem services.

Cluster-3 in Figure-5 shows "Biodiversity" and "Conservation" as their main keywords that can distinguish this cluster from Cluster-1 and Cluster-2. Table-3 also showing some major keywords 
related to "Biodiversity" and "Conservation" such as, "Crop pollination", "Plant diversity", and "Species richness".

Cluster- 4 shows the same main keywords as Cluster- 3 which is "Biodiversity" and "Conservation", but the result in multiword in Table-3 shows some differences. Major keywords in Table-3 such as: "Poverty alleviation", "Water resource management", and "Governing ecosystem" indicate that this cluster can be interpreted as ecosystem services impact to human well-being.

Cluster-5 shows "Climate change" as its main keywords. In Table-3, some major keywords occur such as, "Integrating ecosystem" and "Mainstreaming ecosystem" indicate that this cluster is about climate change and how to react in term of ecosystem.

Cluster- 6 shows "Urban" as its main keywords. This is corresponding with the Table-3 with major keywords such as; "Urban ecosystem", "Green infrastructure", and "Hedonic pricing". So it can be interpreted that this cluster is about the ecosystem in urban areas.

To validate the interpretation, some major publications from each cluster were also used as a comparison. These publications are shown in the Table-4 below:

Table-4 Three most important articles in each cluster

\begin{tabular}{|c|c|}
\hline $\begin{array}{l}\text { Clu } \\
\text { ster }\end{array}$ & Publications \\
\hline 1 & $\begin{array}{l}\text { - The value of the world's ecosystem services and natural capital (Costanza et al., 1997) } \\
\text { - The value of estuarine and coastal ecosystem services (Barbier et al., 2011) } \\
\text { - Defining and classifying ecosystem services for decision making (Fisher et al., 2009) }\end{array}$ \\
\hline 2 & $\begin{array}{l}\text { - Challenges in integrating the concept of ecosystem services and values in landscape } \\
\text { planning, management and decision making (de Groot et al., 2010) } \\
\text { - Mapping ecosystem services for policy support and decision making in the European } \\
\text { Union (Maes et al., 2012) } \\
\text { - Assessing, mapping, and quantifying cultural ecosystem services at community level } \\
\text { (Plieninger et al., 2013) }\end{array}$ \\
\hline 3 & $\begin{array}{l}\text { - Impacts of biodiversity loss on ocean ecosystem services (Worm et al., 2006) } \\
\text { - Managing ecosystem services: what do we need to know about their ecology? (Kremen, } \\
\text { 2005) } \\
\text { - Pollination and other ecosystem services produced by mobile organisms: a conceptual } \\
\text { framework for the effects of land-use change (Kremen et al., 2007) }\end{array}$ \\
\hline 4 & $\begin{array}{l}\text { - Ecosystem services in decision making: time to deliver (Daily et al., 2009) } \\
\text { - The history of ecosystem services in economic theory and practice: from early notions to } \\
\text { markets and payment schemes (Gómez-Baggethun et al., 2010) } \\
\text { - Ecological and socioeconomic effects of china's policies for ecosystem services (Liu et al., } \\
\text { 2008) }\end{array}$ \\
\hline 5 & $\begin{array}{l}\text { - Science for managing ecosystem services: beyond the millennium ecosystem assessment } \\
\text { (Carpenter et al., 2009) } \\
\text { - What are ecosystem services? the need for standardized environmental accounting units } \\
\text { (Boyd and Banzhaf, 2007) } \\
\text { - Understanding relationships among multiple ecosystem services (Bennett et al., 2009) }\end{array}$ \\
\hline 6 & $\begin{array}{l}\text { - Classifying and valuing ecosystem services for urban planning (Gómez-Baggethun and } \\
\text { Barton, 2013) } \\
\text { - Coupling biogeochemical cycles in urban environments: ecosystem services, green } \\
\text { solutions, and misconceptions (Pataki et al., 2011) } \\
\text { - Urban forests and pollution mitigation: analyzing ecosystem services and disservices } \\
\text { (Escobedo et al., 2011) }\end{array}$ \\
\hline
\end{tabular}




\subsection{Citation Network}

Citation network was created using CitNetExplorer. Unlike bibliographic coupling which is an indirect relationship, citation network analysis was made using direct citation. The most important publications in this field were visualized and show the citation relations between these publications to indicate how publication build on each other.

Using the same dataset, 4203 publications are analyzed with a minimum number of citations of 10 . The result is 5700 publications plotted in the Figure- 6 below. The number is higher compared to the input because citation network analysis also plots the references.

In Figure-6, citation relation between publications of ecosystem services from the year 1977 to 2018 are shown. By default, CitNetExplorer only shows top 40 publications with the highest citation score. Citation score is equal to the number of citations received from all publication in the Web of Science database. The result of top 40 publications was the article from the year 1997-2014. Important articles before 1997 and after 2014 needed to be added manually. Selected articles plotted in the graph can be seen here.

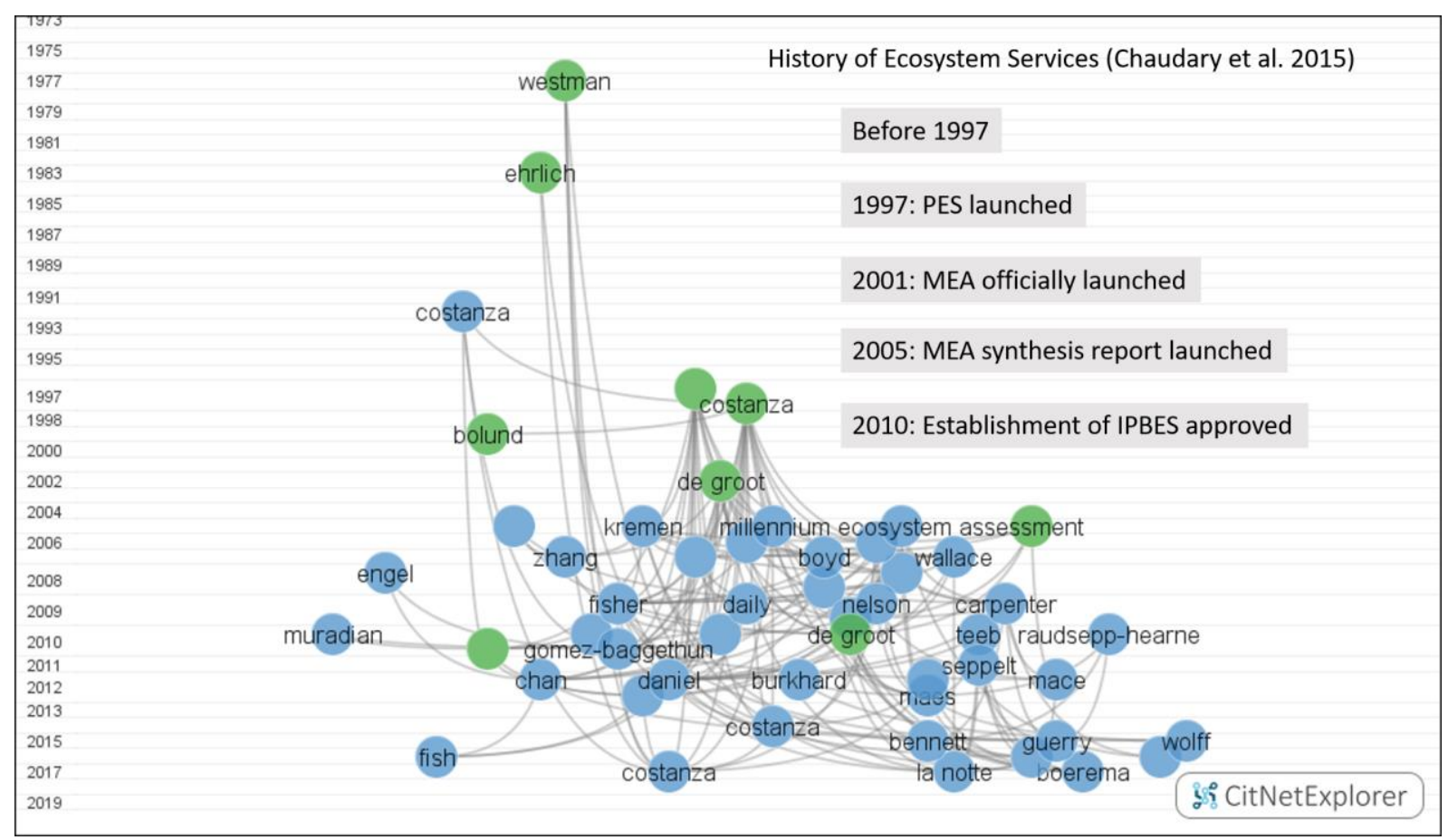

Figure-6 Citation network of ecosystem services publications compared with review paper (green dots) from Chaudry et al (2015).

From the citation network above, we can see how ecosystem services field has been developing over time. Each dots are representing one document with the first author of the documents as the label. The line is indicating the relationship between publications. The green color in Figure- 6 is a symbol for publications cited by Chaudhary et al. (2015) in their publication about the evolution of ecosystem services research, which was used as a comparison. Chaudhary et al. (2015) also mark the year when something happened in the field of ecosystem services.

The information about predecessor of ecosystem services research was obtained. While this topic can be traced back to the seventies, the topic itself not so much developed until 1997. Publications published before 1997 has low citation score compare to publications from after 1997.

The book from Gretchen Daily, Nature's Services: Societal Dependence on Natural Ecosystem (Daily, 1997) can be considered as the mother of ecosystem services research along with publications from 
Costanza, the value of the world's ecosystem services and natural capital (Costanza et al., 1997). These two publications have the highest citation score compare to other publications.

\section{Discussion}

Co-occurrence of text is a strong tool to obtain an overview of a topic. This analysis was quite straightforward and does not need any processing. Apart from the distinguishable cluster maps, it is not so easy to deduce one main title of each cluster, except some obvious cluster which contains some specific keywords. Using this method, major ideas of ecosystem services research can be extracted.

It was expected in the beginning to obtain one keyword or phrase to represent each cluster. However, it is not possible since the result of this analysis a list of keywords with occurrences frequency. In order to obtain the main idea, one can use the most frequent keywords in each cluster, but still, this is not what expected in the beginning.

The result of bibliographic coupling analysis was clusters of documents. List of first author and year of publications might mean nothing to one without knowledge to the subject, therefore analysis of the title of the publications was conducted using natural language processing. This was done to obtain a comparable result with the co-occurrence of text analysis that was performed earlier.

Although the process was not quite straightforward, the result gives more insight about information contained in each cluster and the most influential authors in each cluster. Also, it is possible to obtain lesser keywords as the idea of the cluster.

Using bibliographic coupling, six main ideas of ecosystem services research was extracted. The largest cluster, cluster-1, discuss ecosystem services assessment in term of economic assessment, especially as natural capital. Cluster-2 also discuss ecosystem services assessment but more specific to management and accounting perspective. Cluster-3 discuss biodiversity conservation closely related to species richness and its impact. Cluster- 4 discuss biodiversity conservation in relation to human well-being. Cluster- 5 discuss ecosystem services and climate change, and Cluster- 6 discuss ecosystem services in urban area.

It is important to realize that clustering is not the main purpose of this study. It is just a method to simplify the process of understanding a lot of data, so that insight can be obtained. The statistical algorithm behind the software enables us to create as many clusters as possible. However, more cluster is harder to interpret, therefore clustering is very much dependent on a certain subjectivity. Another thing to be concerned is that extracting keywords causes loss of information, which is the cost of simplicity.

Nevertheless, clustering method using bibliometric analysis is an excellent way to show the big picture of such a huge dataset. Without the urge to read all the publications, which can consume tons of working hour, we still can generate a big picture of one big topic.

Citation network (Figure-6) provides chronological order on how ecosystem services topic has been developing over time. However, to understand information behind the map we need to compare it with references.

In general ecosystem services research stages can be divided into 3 periods, origins and gestation of the modern ES concept (1970 - 1990), ES in regular scientific agenda (1990 - 2000), and ES in decision making (2000 - now) (Gómez-Baggethun et al., 2010). Some key event that remark the development of ecosystem services are; 1997 when Payment for Ecosystem Services (PES) was launched; 2001 when Millennium Ecosystem Assessment (MEA) was launched; 2005 when MEA synthesis report was 
launched; 2010 when establishment of Intergovernmental Science-Policy Platform on Biodiversity and Ecosystem Services (IPBES) approved (Chaudhary et al., 2015).

This time frame is important if one wants to combine text mining and citation network in further research. The dataset can be divided according to the event in ecosystem services; before PES was launched, before MEA was launched, before MEA synthesis report was launched, and before the establishment of IPBES. Using this approach, the citation network can be interpreted not only its key authors but also the content of the articles.

\section{Conclusions}

The dataset of ecosystem services publication is a huge database that can be analyzed to obtain insight into this topic. In this paper, I have performed text mining analysis, bibliographic coupling analysis, and citation network analysis, and in doing so, raised a question about what this huge database tells us. Tons of keywords was plotted, clustered, and therefore make it easier to interpret. The same with documents, represented by the first author, were plotted and clustered, enable us to get insight on who wrote what. And finally, the citation network provides excellent chronological plot on how a topic has been developing over time.

Ecosystem services research has been developing since the 1970s. Since then, many publications in different topic has published. According to the text mining and bibliographic coupling, we can say that ecosystem services topic can be divided into 6 clusters: economic assessment of ecosystem services as natural capital, ecosystem services assessment in term of accounting and management, biodiversity conservation in term of species richness, biodiversity conservation in term of human well-being, climate change and ecosystem services, and ecosystem services in urban area.

Ecosystem services publications were ordered chronologically and it can be concluded that publication from (Costanza et al., 1997; Daily, 1997) can be considered as the most important publications as these two publications have the highest citation score.

\section{Bibliometric Visualization for Your Own Research}

It is important to realize that bibliometric study is different with literature review, it is safe to say bibliometric study is the part of literature review or one aspect that can make literature review process to become more focus and easy. Figuring out how a topic has been developing and important publications that need to be read is also the huge advantage of bibliometric study.

The application of bibliometric study is not limited to what was presented here. As publication dataset is growing and can be accessed, many analyses is potential to be performed. Besides analysis of one specific topic, one can also analyze specific institution, the relationship between institutions, or even between nations. This might be very useful for those who are looking for a doctoral study or postdoctoral study.

Another importance of this technique is that as research publications grow at a very high rate, textmining will become very important as this will be one of the techniques on how we read publication.

\section{References}

Barbier, E.B., Hacker, S.D., Kennedy, C., Koch, E.W., Stier, A.C., Silliman, B.R., 2011. The value of estuarine and coastal ecosystem services. Ecological Monographs 81, 169-193. https://doi.org/10.1890/10-1510.1

Bennett, E.M., Peterson, G.D., Gordon, L.J., 2009. Understanding relationships among multiple ecosystem services: Relationships among multiple ecosystem services. Ecology Letters 12, 1394-1404. https://doi.org/10.1111/j.1461-0248.2009.01387.x 
Boyd, J., Banzhaf, S., 2007. What are ecosystem services? The need for standardized environmental accounting units. Ecological Economics 63, 616-626. https://doi.org/10.1016/j.ecolecon.2007.01.002

Carpenter, S.R., Mooney, H.A., Agard, J., Capistrano, D., DeFries, R.S., Diaz, S., Dietz, T., Duraiappah, A.K., Oteng-Yeboah, A., Pereira, H.M., Perrings, C., Reid, W.V., Sarukhan, J., Scholes, R.J., Whyte, A., 2009. Science for managing ecosystem services: Beyond the Millennium Ecosystem Assessment. Proceedings of the National Academy of Sciences 106, 1305-1312. https://doi.org/10.1073/pnas.0808772106

Chaudhary, S., McGregor, A., Houston, D., Chettri, N., 2015. The evolution of ecosystem services: A time series and discourse-centered analysis. Environmental Science \& Policy 54, 25-34. https://doi.org/10.1016/j.envsci.2015.04.025

Costanza, R., Limburg, K., Naeem, S., O’Neill, R.V., Paruelo, J., Raskin, R.G., Sutton, P., 1997. The value of the world's ecosystem services and natural capital 387, 8 .

Daily, G.C., 1997. Introduction: What Are Ecosystem Services, in: Nature's Services: Societal Dependence on Natural Ecosystems. Island Press.

Daily, G.C., Polasky, S., Goldstein, J., Kareiva, P.M., Mooney, H.A., Pejchar, L., Ricketts, T.H., Salzman, J., Shallenberger, R., 2009. Ecosystem services in decision making: time to deliver. Frontiers in Ecology and the Environment 7, 21-28. https://doi.org/10.1890/080025

de Groot, R.S., Alkemade, R., Braat, L., Hein, L., Willemen, L., 2010. Challenges in integrating the concept of ecosystem services and values in landscape planning, management and decision making. Ecological Complexity 7, 260-272. https://doi.org/10.1016/j.ecocom.2009.10.006

Escobedo, F.J., Kroeger, T., Wagner, J.E., 2011. Urban forests and pollution mitigation: Analyzing ecosystem services and disservices. Environmental Pollution 159, 2078-2087. https://doi.org/10.1016/j.envpol.2011.01.010

Fisher, B., Turner, R.K., Morling, P., 2009. Defining and classifying ecosystem services for decision making. Ecological Economics 68, 643-653. https://doi.org/10.1016/j.ecolecon.2008.09.014

Garfield, E., 2001. From Bibliographic Coupling to Co-Citation Analysis via Algorithmic HistorioBibliography. A Citationist's Triute to Belver C. Griffith.

Gómez-Baggethun, E., Barton, D.N., 2013. Classifying and valuing ecosystem services for urban planning. Ecological Economics 86, 235-245. https://doi.org/10.1016/j.ecolecon.2012.08.019

Gómez-Baggethun, E., de Groot, R., Lomas, P.L., Montes, C., 2010. The history of ecosystem services in economic theory and practice: From early notions to markets and payment schemes. Ecological Economics 69, 1209-1218. https://doi.org/10.1016/j.ecolecon.2009.11.007

Jarneving, B., 2007. Bibliographic coupling and its application to research-front and other core documents. Journal of Informetrics 1, 287-307. https://doi.org/10.1016/j.joi.2007.07.004

Kessler, M.M., 1963. Bibliographic coupling between scientific papers. American Documentation 14.

Kremen, C., 2005. Managing ecosystem services: what do we need to know about their ecology?: Ecology of ecosystem services. Ecology Letters 8, 468-479. https://doi.org/10.1111/j.14610248.2005.00751.x

Kremen, C., Williams, N.M., Aizen, M.A., Gemmill-Herren, B., LeBuhn, G., Minckley, R., Packer, L., Potts, S.G., Roulston, T., Steffan-Dewenter, I., Vázquez, D.P., Winfree, R., Adams, L., Crone, E.E., Greenleaf, S.S., Keitt, T.H., Klein, A.-M., Regetz, J., Ricketts, T.H., 2007. Pollination and other ecosystem services produced by mobile organisms: a conceptual framework for the effects of land-use change. Ecology Letters 10, 299-314. https://doi.org/10.1111/j.14610248.2007.01018.x

Liu, J., Li, S., Ouyang, Z., Tam, C., Chen, X., 2008. Ecological and socioeconomic effects of China's policies for ecosystem services. Proceedings of the National Academy of Sciences 105, 94779482. https://doi.org/10.1073/pnas.0706436105

Maes, J., Egoh, B., Willemen, L., Liquete, C., Vihervaara, P., Schägner, J.P., Grizzetti, B., Drakou, E.G., Notte, A.L., Zulian, G., Bouraoui, F., Luisa Paracchini, M., Braat, L., Bidoglio, G., 2012. Mapping ecosystem services for policy support and decision making in the European Union. Ecosystem Services 1, 31-39. https://doi.org/10.1016/j.ecoser.2012.06.004

Millennium Ecosystem Assessment (Program) (Ed.), 2005. Ecosystems and human well-being: synthesis. Island Press, Washington, DC.

Pataki, D.E., Carreiro, M.M., Cherrier, J., Grulke, N.E., Jennings, V., Pincetl, S., Pouyat, R.V., Whitlow, T.H., Zipperer, W.C., 2011. Coupling biogeochemical cycles in urban environments: ecosystem 
services, green solutions, and misconceptions. Frontiers in Ecology and the Environment 9, 27 36. https://doi.org/10.1890/090220

Plieninger, T., Dijks, S., Oteros-Rozas, E., Bieling, C., 2013. Assessing, mapping, and quantifying cultural ecosystem services at community level. Land Use Policy 33, 118-129. https://doi.org/10.1016/j.landusepol.2012.12.013

van Eck, N.J., Waltman, L., 2014a. Visualizing Bibliometric Networks, in: Ding, Y., Rousseau, R., Wolfram, D. (Eds.), Measuring Scholarly Impact. Springer International Publishing, Cham, pp. 285-320. https://doi.org/10.1007/978-3-319-10377-8_13

van Eck, N.J., Waltman, L., 2014b. CitNetExplorer: A new software tool for analyzing and visualizing citation networks. Journal of Informetrics 8, 802-823. https://doi.org/10.1016/j.joi.2014.07.006

van Eck, N.J., Waltman, L., 2010. Software survey: VOSviewer, a computer program for bibliometric mapping. Scientometrics 84, 523-538. https://doi.org/10.1007/s11192-009-0146-3

van Eck, N.J., Waltman, L., Dekker, R., van den Berg, J., 2010. A comparison of two techniques for bibliometric mapping: Multidimensional scaling and VOS. Journal of the American Society for Information Science and Technology 61, 2405-2416. https://doi.org/10.1002/asi.21421

Waaijer, C.J.F., Palmblad, M., 2015. Bibliometric Mapping: Eight Decades of Analytical Chemistry, With Special Focus on the Use of Mass Spectrometry. Analytical Chemistry 87, 4588-4596. https://doi.org/10.1021/ac5040314

Weinberg, B.H., 1974. Bibliographic coupling: A review. Information Storage and Retrieval 10, 189196. https://doi.org/10.1016/0020-0271(74)90058-8

Westergaard, D., Stærfeldt, H.-H., Tønsberg, C., Jensen, L.J., Brunak, S., 2018. A comprehensive and quantitative comparison of text-mining in 15 million full-text articles versus their corresponding abstracts. PLOS Computational Biology 14, e1005962. https://doi.org/10.1371/journal.pcbi.1005962

Wood, S.L.R., Jones, S.K., Johnson, J.A., Brauman, K.A., Chaplin-Kramer, R., Fremier, A., Girvetz, E., Gordon, L.J., Kappel, C.V., Mandle, L., Mulligan, M., O’Farrell, P., Smith, W.K., Willemen, L., Zhang, W., DeClerck, F.A., 2018. Distilling the role of ecosystem services in the Sustainable $\begin{array}{lllll}\text { Development } \quad \text { Goals. } & \text { Ecosystem }\end{array}$ https://doi.org/10.1016/j.ecoser.2017.10.010

Worm, B., Barbier, E.B., Beaumont, N., Duffy, J.E., Folke, C., Halpern, B.S., Jackson, J.B.C., Lotze, H.K., Micheli, F., Palumbi, S.R., Sala, E., Selkoe, K.A., Stachowicz, J.J., Watson, R., 2006. Impacts of Biodiversity Loss on Ocean Ecosystem Services. Science 314, 787-790. https://doi.org/10.1126/science.1132294 